\title{
EXPERIMENTAL STUDIES ON SNOW ACCRETION AT SUBZERO TEMPERATURES
}

\author{
by \\ Yukiko Mizuno and Gorow Wakahama \\ (Institute of Low Temperature Science, Hokkaido University, Sapporo, Japan 060)
}

\section{ABSTRACT}

In order to clarify the process of snow accretion, which occurs at a temperature below the melting point of ice, experimental studies were made on the microscopic process of ice adhesion as well as the tensile adhesive strength of snow onto various kinds of materials.

For this purpose, direct observations were made of the formation of an ice bond developed at the interface between an ice particle and a plate made of a transparent material such as glass, acrylic plastic (polymethyl methacrylate (PMMA)), or ice, and measurements made of the growth rate of the real contact area.

The growth rate of an ice bond formed at the interface between an ice particle and the plate of a hydrophilic material such as glass was equal to or slightly larger than that of ice sintering, while an ice bond was not formed at the interface between an ice particle and the plate of a hydrophobic material such as teflon.

As for adhesive strength, with the lapse of time it increased rapidly at the former interface and slowly at the latter interface. Examinations of fracture planes revealed that at or near the interface a pure adhesive break did not take place with the exception of teflon and vinyl, and that what took place there was a cohesive break or a mixture of cohesive and adhesive breaks.

\section{INTRODUCTION}

Snow is a highly adhesive material. When it is wet, it contains some free water, and is particularly adherent to other materials including hydrophobic ones. Even when it is dry and does not contain free water, at subzero temperatures such as -5 and $-10^{\circ} \mathrm{C}$, it easily adheres onto most materials, if in contact for some period of time. For instance, falling snowflakes and drifting snow particles which are whirled up by a moving train or automobile easily accrete onto electric wires, telephone lines, parabolic antennae, onto the trains and automobiles themselves and onto other structures. Much trouble and inconvenience can result from this.

Although extensive studies on the prevention of ice accretion have been conducted (Raraty and Tabor 1958, Jellinek 1959, 1962, 1970, Baker and others 1962, Landy and Freiberger 1967), only a limited number of papers have dealt with snow accretion (Shoda 1953, Inoue and Honda 1955, Wakahama and Mizuno 1979). This paper presents the results of studies of the microscopic process of adhesion of ice particles in relation to the tensile adhesive strength of snow onto various kinds of materials both hydrophilic and hydrophobic, including glass, some metals, plastics, and rubber which were brought into contact with a snow sample for some time at different subzero temperatures $\left(-5\right.$ and $\left.-10^{\circ} \mathrm{C}\right)$.

EXPERIMENTAL PROCEDURES AND RESULTS 1. Direct observation of formation of an ice bond at the interface

Ice particles from 100 to $500 \mu \mathrm{m}$ in diameter were prepared by spraying droplets of distilled water into liquid nitrogen. The collected particles were separately placed on a clean teflon sheet, so that they were prevented from aggregating each other, and annealed at $-5^{\circ} \mathrm{C}$ for more than two weeks.

The ice particles were then scattered uniformly on the bottom of a shallow chamber, $75 \times 25 \times 1.2 \mathrm{~mm}$ in size, composed of transparent plates made of a material such as glass, acrylic plastic or ice. The chamber was inverted over a glass slide placed on the stage of a microscope (Fig.1). By focusing on the interface between the bottom of the chamber and the ice particles, the real contact areas between them were easily observed throughout the experiment.

Since any noticeable change in size and shape of the ice particles due to evaporation was not observed for several days, it is considered likely that the air inside the chamber was ice-saturated and that this condition was also maintained at the surface covered with an amount of deposited snow.

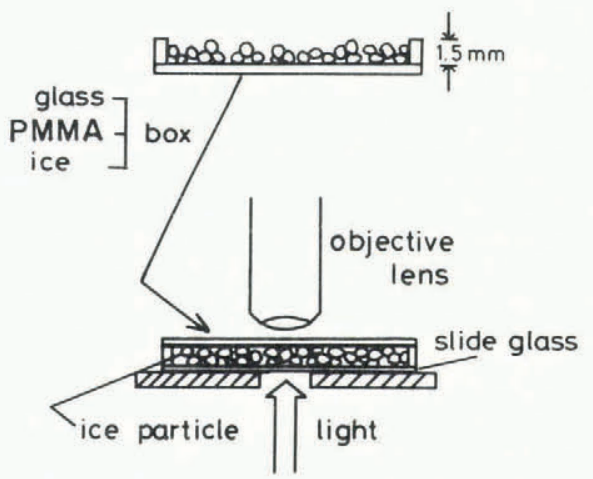

Fig.1. Schematic illustration of the chamber with the top removed and how it is used for observation of a contact area between an ice particle and a plate of transparent material. 
A few minutes after the start of the experiment, a mirror-like real contact area appeared at the interface between an ice particle and the plate of glass (or acrylic plastic or ice) and it grew as illustrated in Figures 2 (ice to glass) and 3 (ice to ice). The mean diameter of each contact area, $2 x$, was measured for ice particles approximately $200 \mu \mathrm{m}$ in diameter and plotted against time $t(\min )$ in Figure 4 , where $R$ is the radius of the ice particle. The linear relationship between $\log (x / R)$ and $\log t$ was found as shown in the figure. The slope of each line is approximately $1 / 5$ for glass and ice and $1 / 7$ for acrylic plastic.

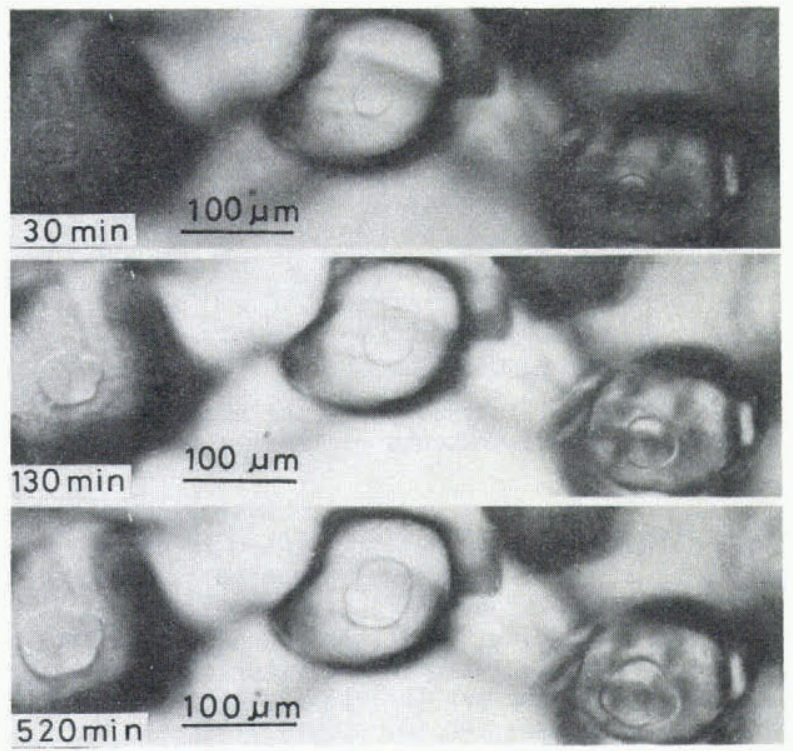

Fig.2. Microphotographs in time sequence of real contact areas at the interface between ice and glass $\left(-10^{\circ} \mathrm{C}\right)$.

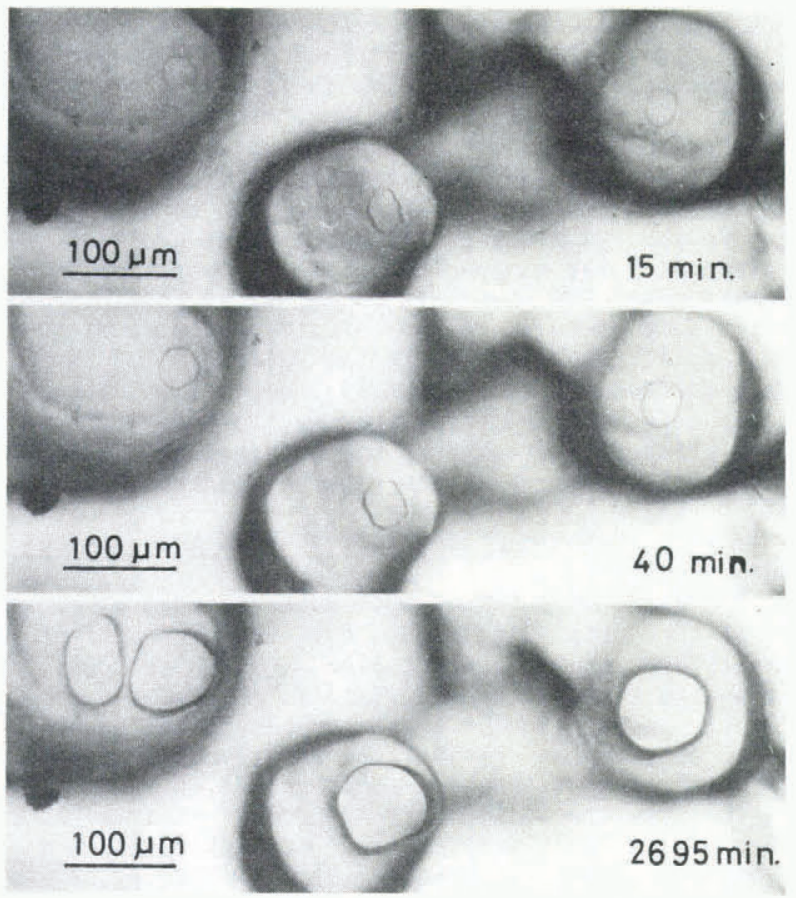

Fig.3. Microphotographs in time sequence of real contact areas between ice particles and an ice plate $\left(-10^{\circ} \mathrm{C}\right)$.
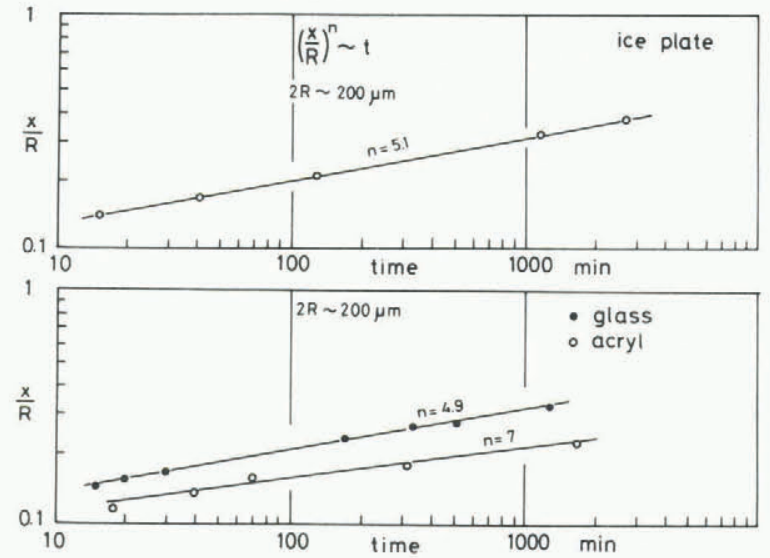

Fig.4. Growth rate of ice bond between an ice particle and a plate made of glass, acrylic plastic or ice $\left(-10^{\circ} \mathrm{C}\right)$.
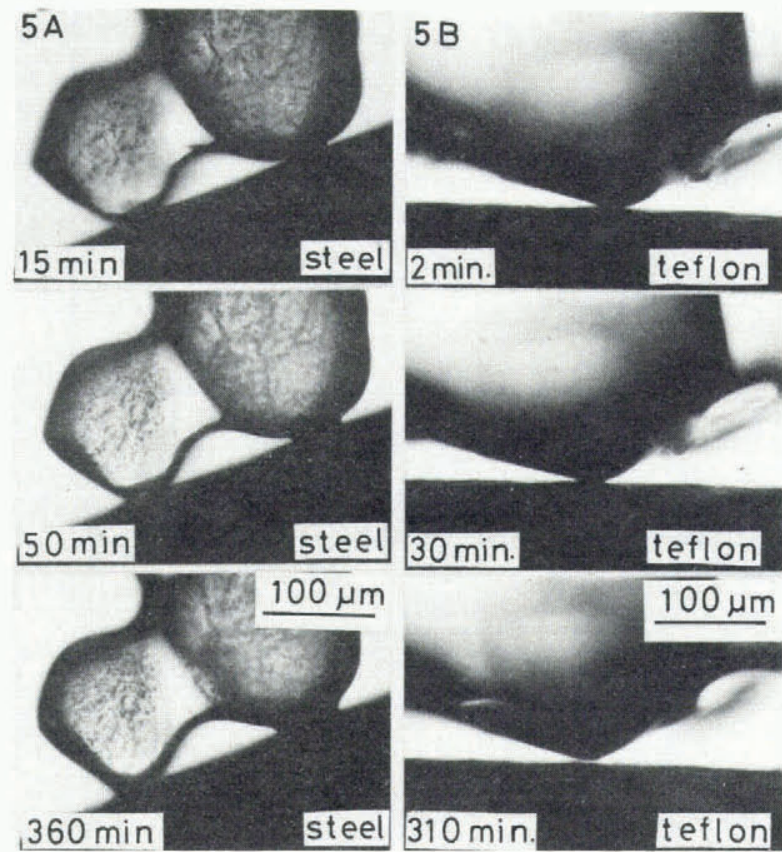

Fig.5. Microphotographs in time sequence of a contact point between an ice particle and a steel plate $(A)$ and a teflon plate $(B)\left(-10^{\circ} \mathrm{C}\right)$.

This method does not allow direct observation of the real contact area between an ice particle and a plate made of an opaque material such as rubber, teflon, metal, and some plastics; an ice bond at the interface was laterally observed under the microscope as illustrated in Figure $5(A)$, which shows the growth of a neck between an ice particle and a steel bar. In the case of some hydrophobic materials such as teflon, an ice bond did not grow at the interface as shown in Figure 5(B).

Adhesion of an ice particle to the ice plate represents, in other words, sintering of ice. It may be assumed that a contact plane is also formed by the same mechanism at the interface of two different materials.

The general form of the equation of sintering proposed by Kuczynski (1949) is

$$
(x / R)^{n}=B(T) t / R^{m}
$$

where $B(T)$ contains temperature-dependent parameters. The value of $m$ in Equation (1) can be found by deter- 
mining how the size of ice particles influences the time required for the contact plane to attain a given value. The time required for attaining the stage at which $x / R=0.2$ at $-10^{\circ} \mathrm{C}$ is plotted against the radius of the ice particle in Figures 6 (ice to ice) and 7 (ice to glass). The values of m obtained from Figures 6 and 7 are both about 3. This suggests that

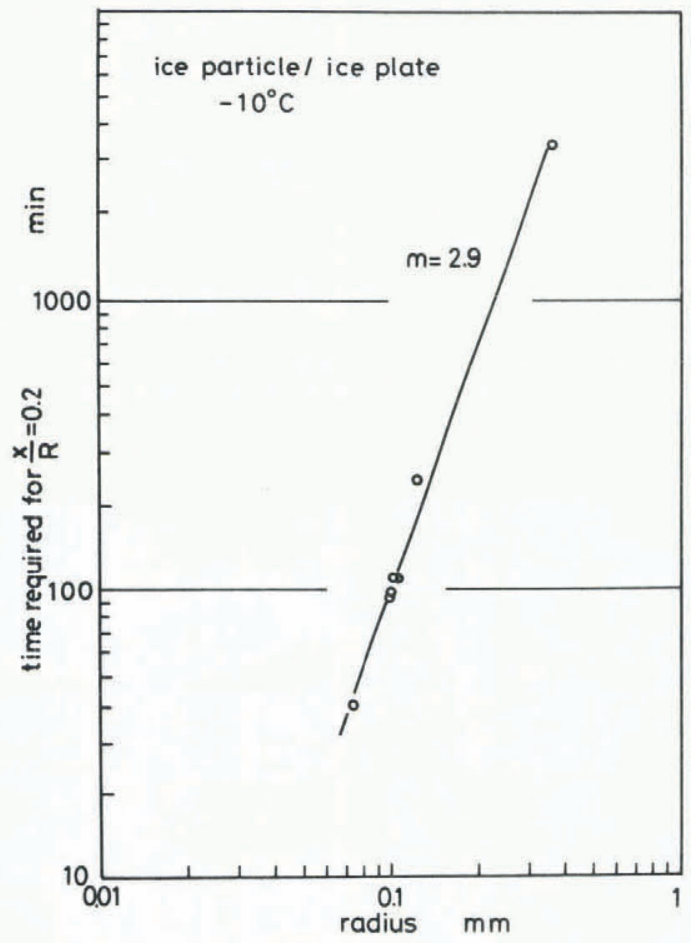

Fig.6. Relationship between time required for the contact plane to attain a given stage $(x / R=0.2)$ and radius of an ice particle, for ice particle to ice plate.

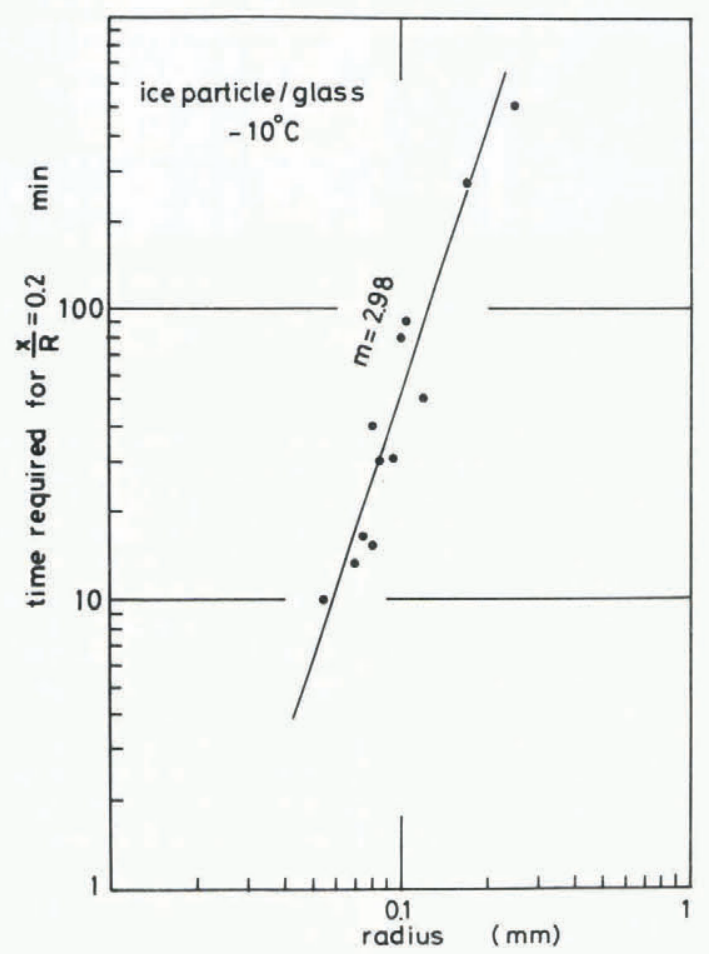

Fig.7. Relationship between time required for the contact plane to attain a given stage $(x / R=0.2)$ and radius of an ice particle, for ice particle to glass. the growth rate of an ice bond at the interface between ice and glass is almost the same as the growth rate in the sintering of ice.

2. Measurement of tensile adhesive strength

The tensile strength of dry snow adhered onto various kinds of hydrophilic (glass, cellulose acetate, aluminium) and hydrophobic (PMMA, silicone rubber, teflon, vinyl) materials was measured at temperatures of $-10^{\circ} \mathrm{C}$ and $-5^{\circ} \mathrm{C}$.

The apparatus is shown schematically in Figure 8.

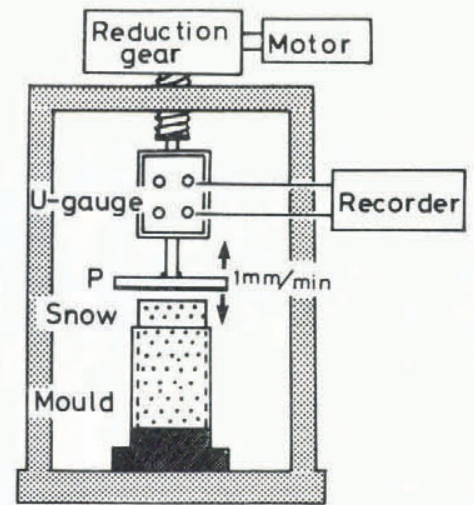

Fig.8. Schematic illustration of the experimental apparatus for measurements of tensile adhesive strength.

A snow column, $0.1 \mathrm{~m}$ in height, $0.05 \mathrm{~m}$ in diameter and $440 \mathrm{~kg} \mathrm{~m}^{-3}$ in density, was prepared as follows: (i) a snow block cut out of a snow cover was disaggregated by sieving, ( $i i)$ the snow particles thus obtained were accumulated in a cylindrical brass mould, and (iii) the top surface of the snow column, which protruded from the mould, was flattened by using a guide and a knife so that it came uniformly into contact with the adhesive plate $P$ in Figure 8 .

In order to produce a good contact between the snow column and the adhesive plate, the snow column was slightly compressed immediately before the adhesion experiment by moving the plate downward at a constant speed of $1 \mathrm{mrn} \mathrm{Inin}^{-1}$ by a motor through reduction gears under which a force-measuring device of the strain-gauge type was placed. When the plate came into contact with the top surface of the snow column, the compressive force began to increase; the stress reached $8 \mathrm{kN} \mathrm{m}^{-2}$ and the motor was stopped. Relaxation of compressive stress took place rapidly, and the pre-compressive force decreased to nearly zero in several minutes. After the plate had been in contact with the top surface of the snow column for a given time, the plate was pulled up by the motor at the same speed as in the case of precompression. The tensile force induced by the pulling up of the plate increased with time until the plate and the snow sample were separated from each other. The tensile adhesive strength $S$ was obtained by dividing the adhesive force $F$ by the apparent contact area $\left(1 \times 10^{-3} \mathrm{~m}^{2}\right)$.

3. Tensile strength of dry snow adhered onto various kinds of materials

Since the strength of snow adhesion onto a specific material depends not only upon the ambient temperature and the contact time Tc but also upon the ageing time of the snow sample Ta, i.e. the time from the preparation of a snow column to the start of the adhesion experiment. The adhesive strength was measured as a function of $\mathrm{Tc}$ and $\mathrm{Ta}$.

The results obtained in the present experiment are shown in Table I for various contact and ageing times. Each value was obtained by taking an average of three measurements for each test, the deviation from the average being within $10 \%$.

Adhesive strengths of dry snow to glass, aluminium and cellulose acetate showed especially large 
TABLE I. TENSILE ADHESIVE STRENGTH OF DRY SNOW ONTO VARIOUS KINDS OF MATERIALS

\begin{tabular}{|c|c|c|c|c|c|c|}
\hline & & $-10^{\circ} \mathrm{C}$ & & & $-5^{\circ} \mathrm{C}$ & \\
\hline Material & $\begin{array}{c}\text { Contact time } \\
\text { TC } \\
(\min )\end{array}$ & $\begin{array}{c}\text { Ageing time } \\
\text { Ta } \\
(\min )\end{array}$ & $\begin{array}{l}\text { Tensile } \\
\text { adhesive } \\
\text { strength } \\
\left(\mathrm{kNm}^{-2}\right)\end{array}$ & $\begin{array}{c}\text { Contact time } \\
\text { TC } \\
\text { (min) }\end{array}$ & $\begin{array}{c}\text { Ageing time } \\
\text { Ta } \\
\text { (min) }\end{array}$ & $\begin{array}{l}\text { Tensile } \\
\text { adhesive } \\
\text { strength } \\
\left(\mathrm{kNm}^{-2}\right)\end{array}$ \\
\hline Glass & $\begin{array}{r}10 \\
10 \\
5 \\
30\end{array}$ & $\begin{array}{l}20 \\
10 \\
10 \\
30\end{array}$ & $\begin{array}{l}2.25 \\
1.60 \\
0.82 \\
8.00\end{array}$ & 10 & 10 & 4.00 \\
\hline Cellulose acetate & $\begin{array}{r}5 \\
30\end{array}$ & $\begin{array}{l}20 \\
30\end{array}$ & $\begin{array}{l}1.22 \\
2.38\end{array}$ & 10 & 10 & 2.90 \\
\hline Aluminium & $\begin{array}{l}10 \\
30\end{array}$ & $\begin{array}{l}20 \\
30\end{array}$ & $\begin{array}{l}2.30 \\
2.60\end{array}$ & 10 & 10 & 0.55 \\
\hline $\begin{array}{l}\text { Acrylic plastic } \\
\text { (PMMA) }\end{array}$ & $\begin{array}{r}10 \\
5 \\
16 \text { hours }\end{array}$ & $\begin{array}{l}20 \\
20\end{array}$ & $\begin{array}{l}0.95 \\
0.61 \\
5.75\end{array}$ & 10 & 10 & 2.30 \\
\hline Silicone rubber & $\begin{array}{l}30 \\
10\end{array}$ & $\begin{array}{l}30 \\
20\end{array}$ & $\begin{array}{l}0.54 \\
0.50\end{array}$ & 10 & 10 & 0.50 \\
\hline $\begin{array}{l}\text { Teflon } \\
\text { Vinyl }\end{array}$ & $\begin{array}{l}30 \\
30\end{array}$ & $\begin{array}{l}30 \\
30\end{array}$ & $\begin{array}{l}0 \\
0\end{array}$ & $\begin{array}{l}30 \\
30\end{array}$ & $\begin{array}{l}30 \\
30\end{array}$ & $\begin{array}{l}0 \\
0\end{array}$ \\
\hline
\end{tabular}

values. Although the direct observation of a contact area between dry snow and aluminium or cellulose acetate was not carried out, it is likely that the ice bond was also formed at the interface in the same manner as between an ice particle and glass.

In contrast with the adhesion to the hydrophilic materials described above, the tensile adhesive strength of dry snow to teflon was so small that it was not possible to measure at either -10 or at $-5^{\circ} \mathrm{C}$ despite a longer contact time. This is shown by the microphotographs of the contact region of an ice particle and teflon (Fig.5(B)), in which the ice bond failed to grow between them. Therefore, it is suggested that the ice bond did not form at the interface between ice and vinyl.

Examination of the fracture planes after the separation of a snow sample revealed that several snow particles always remained at all those surfaces which created the tensile force, while none remained at both the teflon and vinyl surfaces. This strongly suggests that in the present experiment the separation took place not only at the interface but also within the snow sample in the vicinity of the interface; that is, a pure adhesive break seldom occurred except on tefion and vinyl.

\section{DISCUSSION}

The direct observation of the contact area between an ice particle and a specific material reveals that snow adheres directly, without melting and refreezing, onto the material through the formation of an ice bond at the interface between them. The mechanism or process of snow accretion occurring at the temperature below the melting point of ice is basically different to that which is caused by wet snow. It may be assumed that the mechanism of growth of an ice bond at the interface between ice and another material, i.e. that of accretion of dry snow, is the same as in the case of ice sintering.

The mechanism of ice sintering has been studied extensively by Kingery (1960), Kuroiwa (1961), Hobbs and Mason (1964) and Jellinek and Ibrahim (1967): however, they have all come to different conclusions. Hobbs and Mason pointed out that the mass transfer by evaporation-condensation proposed by Kuczynski (1949) should not be valid for the sintering of ice in air at atmospheric pressure because of its high vapour pressure; they proposed a new evaporationcondensation theory which was applicable when the molecule is transferred from the surface of the sphere to the neck by diffusion through the environmental gas. Considering Cabrera's treatment (1950) of the problem of migration of a molecule by surface diffusion, they proposed that in the case of ice sintering, the condition in which the values of $n$ and $m$ in Equation (1) were equal to 5 and 3 , respectively, was satisfied in all three mechanisms, namely, evaporation-condensation, volume diffusion and surface diffusion. Hobbs and Mason (1964) emphasized that the most likely mechanism had to be determined both on the basis of the observed rate of sintering and the evaluation of the $B(T)$ term in the equation.

$A 1$ though the $B(T)$ terms in each mechanism are different, they are all represented by

$(x / R)^{5}\left(k T / 20 \gamma^{3}\right)\left(R^{3} / t\right)$, where $k$ is the Boltzman constant, $\delta$ the intermolecular spacing, and $\gamma$ the surface energy of ice.

In our experiment on the adhesion of an ice particle to an ice plate, the transport coefficient given by $(x / R)^{5}\left(k T / 20 \gamma \delta^{3}\right)\left(R^{3} / t\right)$ was evaluated as $4.03 \times 10^{-12} \mathrm{~m}^{2} \mathrm{~s}^{-1}$ for $T=263 \mathrm{~K}, \mathrm{R}=0.1 \mathrm{~mm}$, $\gamma=109 \mathrm{~J} \mathrm{~m}^{-2}$ (Ketcham and Hobbs 1969), and the time required for the contact plane to attain the stage is represented by $x / R=0.2$. In the case of adhesion of an ice particle to a glass plate, the values of $n$ and $\mathrm{m}$ are 5 and 3 respectively, but the time required to 
reach $x / R=0.2$ obtained for $T=263 \mathrm{~K}$ and $\mathrm{R}=0.1 \mathrm{~mm}$ is about $70 \mathrm{~min}$ as shown in Figure 7 , which is smaller than that obtained in the case of ice sintering. It strongly suggests that the growth rate of an ice bond between ice and a glass plate is equal to or slightly larger than that of ice sintering. In other words, snow or ice adheres more easily to a glass plate than they aggregate to each other. Since glass is one of the most hydrophilic materials, it is reasonable to consider that both the value of the surface energy between glass and water vapour and the distance of an individual water molecule adsorbed on the surface of the glass plate are nearly equal to those of the ice surface exposed to ice-saturated air.

In comparison with adhesion onto a glass plate, the growth rate of the real contact area on an acrylic plate was much smaller; the value of the parameter $n$ was equal to 7 and the time required to reach $x / R=0.2$ for an ice particle of $0.1 \mathrm{~mm}$ in radius was about $10 \mathrm{~h}$. Incidentally, $n$ was nearly equal to 6 in adhesion onto a steel plate. Furthermore, the formation of an ice bond at the interface between an ice particle and a teflon plate (a typical hydrophobic material) was not observed. Additionally, ice and teflon showed a tendency to separate from the initial contact point.

It seems that the growth rate of the real contact area may depend mainly on the surface energy between a specific material and water vapour which may be closely related to the radius of the neck $\rho$ formed immediately an ice particle comes in contact with the material. Considering the equilibrium contact angle of a water droplet on the surface of the material, the radij of necks formed at each interface between an ice particle and a plate of three different kinds of materials, (glass, acrylic plastic and teflon) are schematically drawn in Figure 9. When the ice

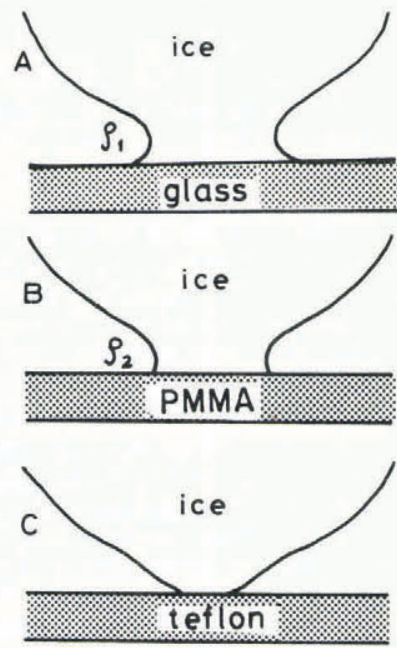

Fig.9. Radii of ice bonds each formed the moment ice comes in contact with three different kinds of materials $\left(\rho_{1}<\rho_{2}\right)$.

particle is kept in contact with a material for which the equilibrium contact angle is smaller than a right angle, such as glass and acrylic plastic, a concave neck may be formed. Meanwhile, it is impossible to make a concave neck between an ice particle and a teflon plate. Therefore, there is no driving force for the water molecule to transfer toward the neck in the case of teflon.

Itagaki (1967) has shown experimentally that the formation of a concave neck is not the only condition for adhesion of ice. He observed the formation of a neck between an ice sphere and an ice plate close to each other but not in contact (about $10 \mu \mathrm{m}$ apart) in an ice-saturated atmosphere. This suggests that snow also adheres onto the surface even if no initial concave curvature is formed between them, and explains why the excess vapour pressure due to the positive curvature of the sphere was able to drive molecules towards the nearby flat surface. A similar phenomenon was observed in our experiment between an ice particle and a glass plate placed close to each other. It seems that an ice particle facing a teflon plate must supply water molecules towards the teflon surface because they are in the same state as that which is maintained in the case of adhesion onto glass. Incoming water molecules from the ice particle, however, cannot remain stable on the teflon surface because of the extremely low surface energy of teflon. As a result, an ice bond is not formed at the interface between them.

The growth rate of the real contact area is controlled not only by the rate of arrival of water molecules but also by the rate at which the latent heat of sublimation liberated at the surface is dispersed. In our experiments at -10 and $-5^{\circ} \mathrm{C}$, in which an ice particle was surrounded by ice-saturated air, it may be considered that the growth rate is mainly controlled by the former. The process of snow accretion at subzero temperatures is strongly dependent on the surface energy of the material in contact with the snow. The thermal conductivity of the material will become relatively more important as the ambient temperature approaches the melting point of ice.

\section{SUMMARY AND CONCLUSIONS}

Microscopic observations of the process of snow or ice adhesion revealed the following. Ice or snow adhere onto materials by forming an ice bond at the interface. Growth rate of an ice bond at the interface between an ice particle and a plate made of some material depends strongly on the surface energy between the material and water vapour. Accretion of dry snow onto glass occurs immediately, and the growth rate of the real contact area is equal to or slightly larger than that of ice sintering, while an ice bond is not grown on the surface of such materials as are marked by small surface energy, such as teflon.

It can be cuncluded that the mechanism of snow accretion at a temperature below the melting point of ice is the same as that of ice sintering.

Measurements of tensile strength of snow onto various kinds of hydrophilic and hydrophobic materials revealed that adhesive strength of dry snow to a specific material depends greatly not only on the ambient temperature and the contact time but also on the ageing time of an adherent snow sample. This dependency on time is the biggest factor in the difference between the accretion of dry and wet snow.

Examination of fracture planes revealed that a pure adhesive break did not take place at the interface, with the exception of teflon and vinyl; a cohesive break or a mixture of cohesive and adhesive breaks occurred at or near the interface. This suggests that the separation of a snow column from some other materials occurs mainly within the snow column, and that the value of adhesive strength reflects directly the tensile strength of adherent snow itself when snow accretes onto a hydrophilic material such as glass.

\section{REFERENCES}

Baker H R, Bascom W D, Singleterry C R 1962 The adhesion of ice to lubricated surfaces. Journal of Colloid science 17(5): 477-491

Cabrera N 1950 Note on surface diffusion in sintering of metallic particles. Transactions of the American Institute of Mining and Metallurgical Engineers 188: 667-668

Hobbs P V, Mason B J 1964 The sintering and adhesion of ice. Philosophical Magazine 9(98): 181-197 
Inoue R, Honda $T 1955$ Kotai-men to sekisetsu no fuchaku-ryoku no jikken [Measurement of adhesion between snow and a solid surface]. Joumal of the Japanese Society of Snow and Ice 17(1): 18-20

Itagaki K 1967 Some surface phenomena of ice. Journal of Colloid and Interface Science 25(2): 218-227

Jell inek H H G 1959 Adhesive properties of ice. Joumat of Colloid Science 14(3): 268-280

Jellinek H H G 1962 Ice adhesion. Canadian Journal of Physics 40(10): 1294-1309

Jellinek H H G 1970 Ice adhesion and abhesion: a survey. In snow removal and ice control research. Proceedings of an international symposium held April 8-10, 1970. Washington, DC, National Academy of Sciences. Highway Research Board: 46-77 (Special Report 115)

Jell inek H H G, Ibrahim S H 1967 Sintering of powdered ice. Journal of Colloid and Interface Science 25(2): 245-254

Ketcham W M, Hobbs P V 1969 An experimental determination of the surface energies of ice. Philosophical Magazine 19(162): 1161-1173

Kingery W D 1960 Regelation, surface diffusion and ice sintering. Journal of Applied Physics 31(5): 833-838

Kuczynski G C 1949 Self-diffusion in sintering of metallic particles. Transactions of the American Institute of Mining and Metallurgical Engineers 185: $169-178$

Kuroiwa D 1961 A study of ice sintering. Tellus 13(2): 252-259

Landy M, Freiberger A 1967 Studies of ice adhesion I. Adhesion of ice to plastics. Jourmal of Colloid and Interface Science 25(2): 231-244

Raraty L E, Tabor D 1958 The adhesion and strength properties of ice. Proceedings of the Royal Society of London Ser A 245(1241): 184-201

Shoda M 1953 Chaku-setsu no kenkyü [Studies on snow accretion]. Seppȳo no Kenkyu 1: 50-72

Wakahama G, Mizuno Y 1979 Studies on tensile strength of wet snow. In Snow removal and ice control research. Proceedings of the second Inter national Symposium... 1978, at Hanover, NH...

Washington DC, National Academy of Sciences: 18-22 (Transportation Research Board. Special Report 185) 